\title{
Influência dos aditivos de consolidação sobre as propriedades termomecânicas da matriz de concretos de projeção
}

\section{(Influence of setting additives on the thermomechanical properties of wet shotcrete refractory castables' matrix)}

\author{
Y. A. Marques, D. Vasques Filho, R. G. Pileggi, V. C. Pandolfelli \\ Departamento de Engenharia de Materiais - DEMa \\ Universidade Federal de $S$. Carlos \\ Rod. Washington Luiz, km 235, C.P. 676, S. Carlos, SP 13565-905 \\ ymarques@polvo.ufscar.br,vicpando@power.ufscar.br
}

Resumo

\begin{abstract}
A projeção a úmido de concretos refratários consiste na aplicação do material na forma de um jato de "spray" sobre uma superfície, resultando numa elevada taxa de instalação e eficiente compactação do material. Esta técnica dispensa o uso de moldes devido à adição de aditivos aceleradores de pega e/ou coagulantes que reduzem rapidamente a fluidez do concreto projetado sobre a superfície. Usualmente, a avaliação do desempenho dos aditivos está relacionada à aderência do concreto sobre a superfície (perda por rebote). Entretanto, diferentes mecanismos de coagulação podem afetar distintamente as propriedades termomecânicas do material. Estudos reportam que características finais do concreto, como a deformação por fluência, estão relacionadas com o teor de matriz. Por estes motivos, o presente trabalho teve como objetivo avaliar o impacto de aditivos coagulantes e aceleradores de pega nas propriedades termomecânicas da matriz de concretos refratários aplicados por projeção. Os resultados obtidos identificaram uma acentuada influência do tipo de aditivo em relação à resistência mecânica e à deformação por fluência em altas temperaturas da matriz. Além disso, foi identificada uma nova classe de aditivos que proporciona melhor desempenho do material quando comparado a aditivos comercialmente utilizados.
\end{abstract}

Palavras-chave: concretos refratários, matriz, projeção, aditivos, propriedades termomecânicas.

Abstract

Wet shotcrete is a technique that consists on spraying the castable on a surface, affording high placing rate and efficient material packing. Wet shotcrete does not require the use of molds due to the presence of accelerating admixtures or coagulants which immediately reduce fluidity of the castable sprayed on the surface. The usual evaluation of the additive performance is based on the amount of material adhered on the surface (rebound loss). However, distinct coagulation mechanisms can affect the thermomechanical properties of the material in different ways. Studies reported that final properties of castables, such as creep flow, are related to the matrix amount. Thus, the purpose of this work was to evaluate the impact of coagulants and accelerating admixtures on the thermomechanical properties of wet shotcrete refractory castables matrix. The results show a great impact of the additives on the mechanical strength and creep of the matrix. Moreover, a new class of shotcrete additives, which promotes a better performance of the material when compared to commercially used admixtures, was identified.

Keywords: refractory castable, shotcrete, additives, thermomechanical properties.

\section{INTRODUÇÃO}

Concretos de projeção foram inicialmente desenvolvidos para indústria de construção civil no início do século XX [1]. Desde então, os avanços da técnica e suas vantagens foram responsáveis pela ampla difusão e utilização dos concretos aplicados por projeção. Entre suas vantagens, destacam-se a alta taxa de instalação, baixo custo, a capacidade de automação, sua ampla utilização em reparos e recobrimentos de superfícies, além das boas propriedades finais do concreto devido a grande compactação do material durante a aplicação [1-4].

A técnica de projeção de concretos a úmido (Fig. 1) consiste em bombear o concreto previamente misturado com a água até o local de aplicação [1,5]. Na saída da tubulação é acoplado um dispositivo (bocal de projeção) que possui uma entrada para ar comprimido (alta pressão), que acelera o concreto formando um "spray" sobre a superfície de recobrimento. A consolidação do material sobre a superfície é proporcionada por um aditivo, responsável pela perda instantânea da fluidez do concreto, também injetado pelo bocal de projeção. Este processo resulta numa elevada taxa de instalação e dispensa a utilização de moldes. Uma característica marcante desta técnica é a reduzida porosidade usualmente verificada no material aplicado, como resultado da alta compactação e menor teor 


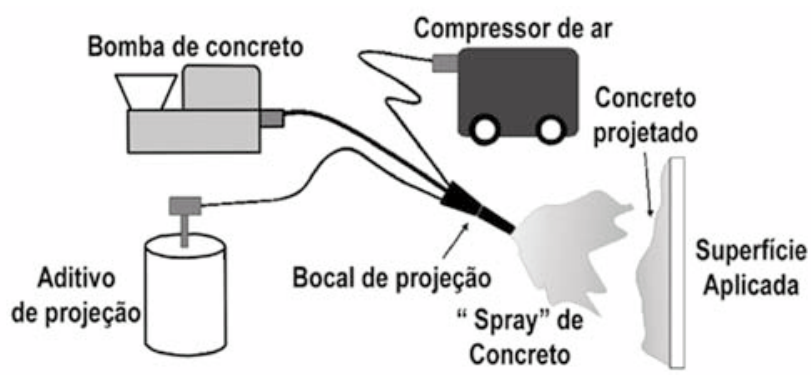

Figura 1: Descrição esquemática do processo de aplicação de concretos refratários por projeção a úmido, destacando as etapas de mistura, bombeamento e projeção [5].

[Figure 1: Schematic description of the wet shotcrete process, pointing out the mixing, pumping and spraying stages [5].]

de água utilizado neste processo [2, 4].

A evolução desta técnica tem despertado grande interesse tecnológico, sobretudo com os avanços alcançados nos concretos bombeáveis, pelo desenvolvimento de análises de reometria e novos equipamentos de bombeamento $[2,5]$. Devido a estes avanços, recentemente, a projeção a úmido ganhou destaque na indústria de refratários juntamente com a utilização crescente de concretos em substituição aos revestimentos monolíticos $[1,6]$.

Independentemente da simplicidade de seu conceito, a aplicação de concretos refratários pela técnica de projeção a úmido é uma tarefa complexa que envolve fenômenos de bombeamento, além da aplicação propriamente dita do concreto. A projeção em si constitui apenas a fase final do processo, sendo que seu desempenho depende das etapas anteriores $[2,6,7]$.

Concretos refratários possuem uma extensa distribuição granulométrica $[5,8]$, uma vez que são compostos por uma matriz (partículas $<100 \mu \mathrm{m}$ - domínio dos fenômenos de superfície e interação com meio líquido) e por agregados (partículas $>100 \mu \mathrm{m}$ - domínio dos fenômenos de massa). Para que a projeção ocorra de maneira adequada, o concreto bombeado deve ser homogêneo, disperso e isento de segregação (separação matriz/agregado) [1,2].

A essência da técnica de projeção está no "spray" de concreto formado em decorrência da geometria cônica do bocal, da elevada taxa de cisalhamento imposta ao material pelo ar comprimido (Figs. 1 e 2) e do aditivo de projeção utilizado. Esta associação de fatores provoca pulverização do concreto em grânulos de agregados recobertos pela matriz, os quais vão colidir sobre a superfície e/ou nas camadas de material já instaladas. Dependendo dos aditivos de projeção, os grânulos podem se comportar como estruturas estáveis ou de transição, sofrendo modificações em sua consistência ao longo de seu trajeto até a superfície. A Fig. 2 ilustra os fenômenos envolvidos na projeção a úmido desde o bombeamento.

A obtenção de tal "spray" depende de fatores associados aos equipamentos (bomba, tubulação e bocal de projeção), dos procedimentos operacionais (pressão do ar comprimido, forma de incorporação do aditivo, direção da aplicação, ângulo de abertura do jato, etc.) e do comportamento reológico e composição da matriz. Uma vez que os aditivos afetam diretamente a reologia do material [4], a projeção e a consolidação do material sobre a superfície dependem também da interação do aditivo de projeção com a matriz.

Usualmente, em aplicações de concreto por projeção a úmido, aditivos aceleradores de hidratação do cimento são utilizados para promover consistência instantânea do concreto $[1,2,4]$. A maior parte destes aceleradores é baseada em compostos alcalinos, e seu desempenho depende da composição química e distribuição granulométrica do cimento [3]. Entretanto, um efeito negativo desta classe de aditivos, é o efeito de diminuição da resistência mecânica final do material projetado, além de afetar a refratariedade no caso de uso a alta

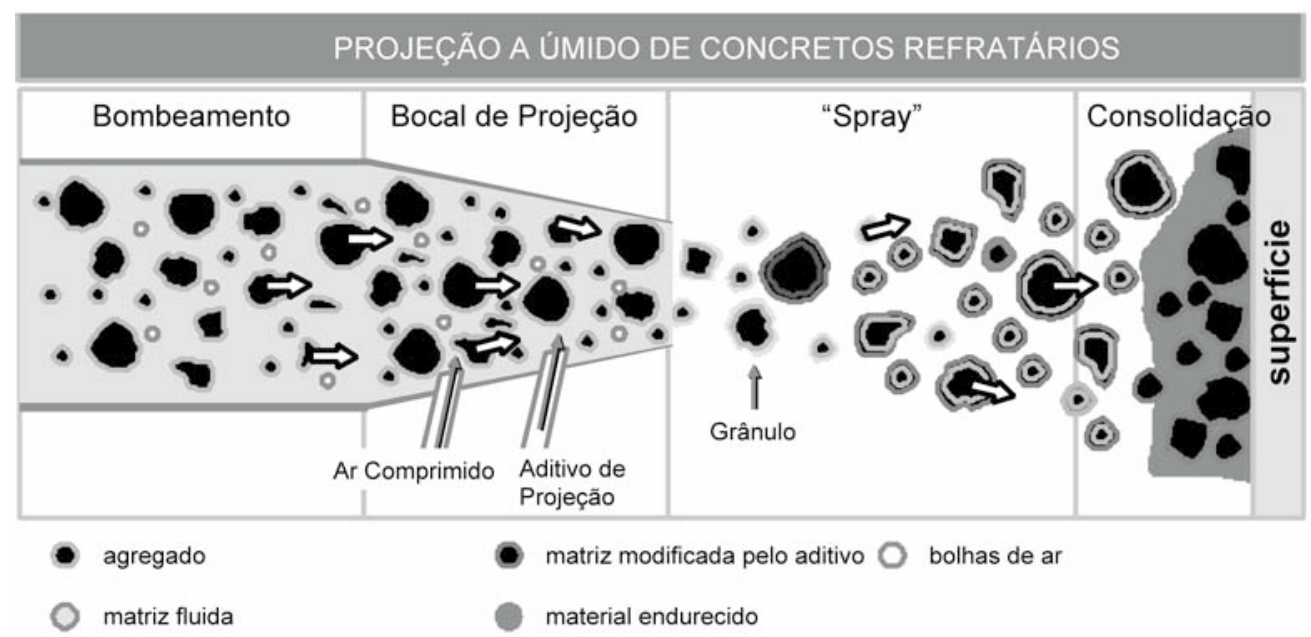

Figura 2: Ilustração esquemática da aplicação de concretos refratários por projeção destacando quatro aspectos da técnica: (a) bombeamento; (b) bocal de projeção; (c) "spray" e (d) consolidação [7]. [Figure 2: Schematic illustration of the wet shotcrete spraying technique of refractory castables: (a) pumping; (b) nozzle; (c) spray and (d) consolidation [7].] 
temperatura. Esse efeito, documentado em literatura [2, 3], tende a aumentar significativamente com o teor do aditivo.

Para minimizar estes efeitos, foram desenvolvidas substâncias "alkalifree", ou seja, isentos de álcalis, que adicionalmente minimizam os riscos relacionados à toxidade de substâncias alcalinas [2,3]. Além de acelerar a hidratação do cimento, esses aditivos atuam por mecanismos de aglomeração, aumentando a força iônica e alterando o pH da suspensão, promovendo maior força de atração das partículas e, desta maneira, afetando diretamente a estrutura de empacotamento do material $[3,4,9]$.

Nos últimos anos, surgiu uma classe de aditivos orgânicos gelificadores do meio líquido desenvolvidos para materiais consolidados por ligantes hidráulicos (cimento) [10]. No concreto, eles atuam formando géis que aprisionam a água e aumentam a viscosidade do meio, promovendo a coesão e aumento da adesão do material. Contudo, esse aprisionamento de água pode retardar a secagem de materiais refratários, aumentando seu tempo de instalação. Alguns destes aditivos geram géis de redes tridimensionais formadas a partir de ligações cruzadas com os íons cálcio do cimento [10,11]. Esse mecanismo reduz a retenção de água, já que a coesão é também promovida pelas ligações químicas formadas.

Recentemente, polieletrólitos orgânicos de cadeia polimérica longa, foram propostos como novos aditivos orgânicos para projeção a úmido de concretos refratários [4, 9]. A extensa cadeia polimérica da molécula adsorvida provoca o estabelecimento de pontes entre as partículas, devido à adsorção de uma mesma cadeia polimérica em parte da superfície de várias partículas (efeito "bridging") [12]. Entretanto, as partículas não se aproximam em demasia devido ao seu efeito estérico, não afetando a estrutura de empacotamento original do material $[9,12]$.

Usualmente, a avaliação do desempenho dos aditivos esta relacionada à adesão do concreto sobre a superfície (perda por rebote) $[1,2,5]$. Diversos trabalhos publicados na literatura $[2-4,6,7]$ têm proposto técnicas e procedimentos que possibilitam o estudo do comportamento dos concretos durante a projeção. Na maioria destes, o concreto é projetado em uma superfície padrão, sendo avaliado a quantidade de material não aderida à superfície [2, 3]. Tal método de avaliação apresenta características empíricas, além de envolver elevado custo, pois requer aplicação de grandes quantidades de material.

A introdução de aditivos de projeção pode ainda afetar outras características do concreto. Recentemente, foram realizados alguns estudos reológicos $[4,5,7]$ sobre a aplicação dos concretos de projeção e a influência dos diferentes mecanismos de coagulação sobre a permeabilidade e velocidade de secagem de refratários [9]. No entanto, restam ainda dúvidas sobre o impacto dos aditivos coagulantes nas propriedades termomecânicas de concretos refratários.

A principal dificuldade relacionada ao estudo das propriedades finais dos concretos de projeção está associada à moldagem de corpos-de-prova, devido à instantânea perda de fluidez do material no momento da introdução do aditivo. Esse fato tem sido contornado pela técnica de prensagem, onde a estrutura de empacotamento das partículas é afetada, não reproduzindo a aplicação real [3,9]. Entretanto, os diferentes mecanismos de coagulação de aditivos de projeção podem influenciar diretamente na estrutura de empacotamento das partículas, afetando, desta maneira, a microestrutura do material.

Resultados de pesquisas anteriormente efetuadas [8], mostram que, tanto a deformação por fluência em altas temperaturas quanto o módulo elástico de concretos refratários formulados com diferentes coeficientes de Andreasen, estão diretamente relacionados com o teor de matriz. Além disso, a deformação final na fluência independe do diâmetro máximo de partículas. Desta maneira, esta propriedade termomecânica dos concretos é influenciada pela fração fina da distribuição granulométrica.

Baseado nessas informações, e no fato da atuação dos aditivos de projeção estar diretamente relacionado com as partículas de granulometria fina $(<100 \mu \mathrm{m})$, supõe-se que é possível isolar os efeitos químicos e estruturais dos mecanismos de coagulação em concretos refratários caracterizando a fração granulométrica correspondente a matriz do material. Desta maneira, este trabalho tem como objetivo avaliar o impacto
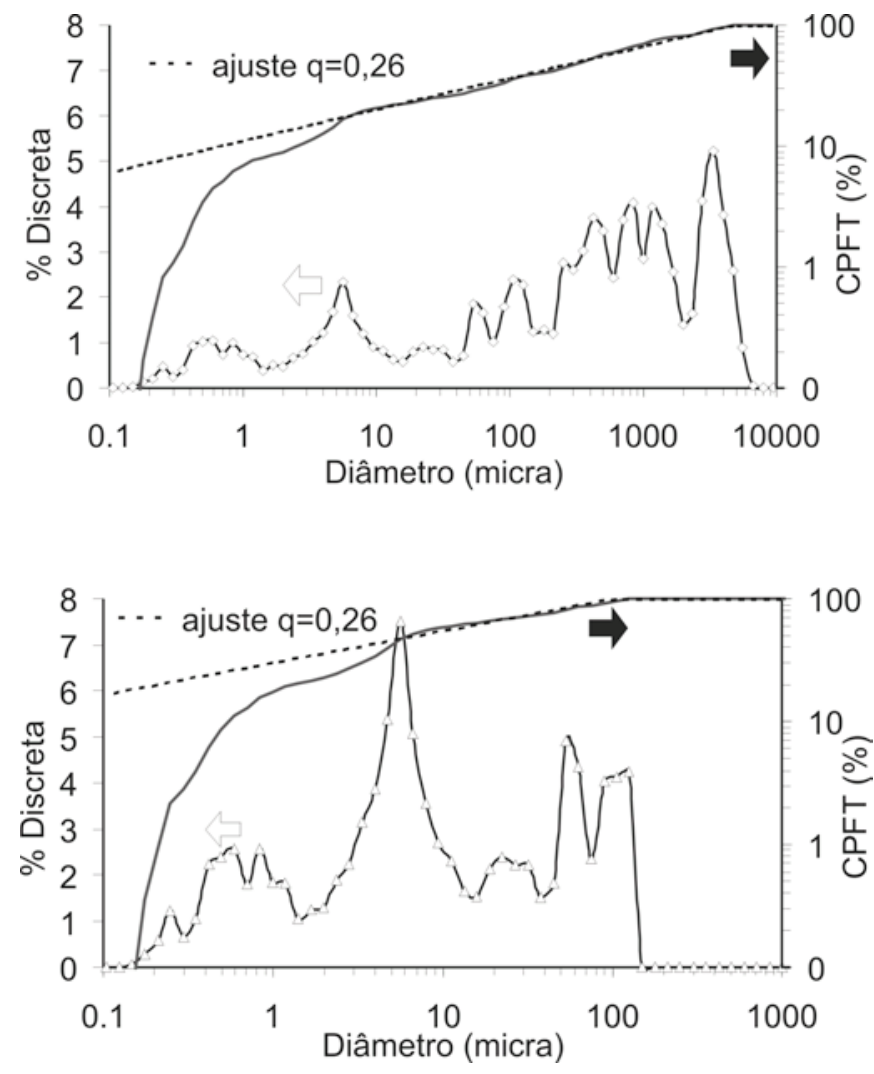

Figura 3: Distribuições granulométricas discreta e acumulada (CPFT\%) (A) do concreto $\mathrm{q}=0,26$ e (B) da matriz $\mathrm{q}=0,26$ utilizada no trabalho.

[Figure 3: Discrete and cumulative (CPFT\%) particle size distribution of the (A) $q=0.26$ castable and (B) $q=0.26$ matrix used in the work.] 

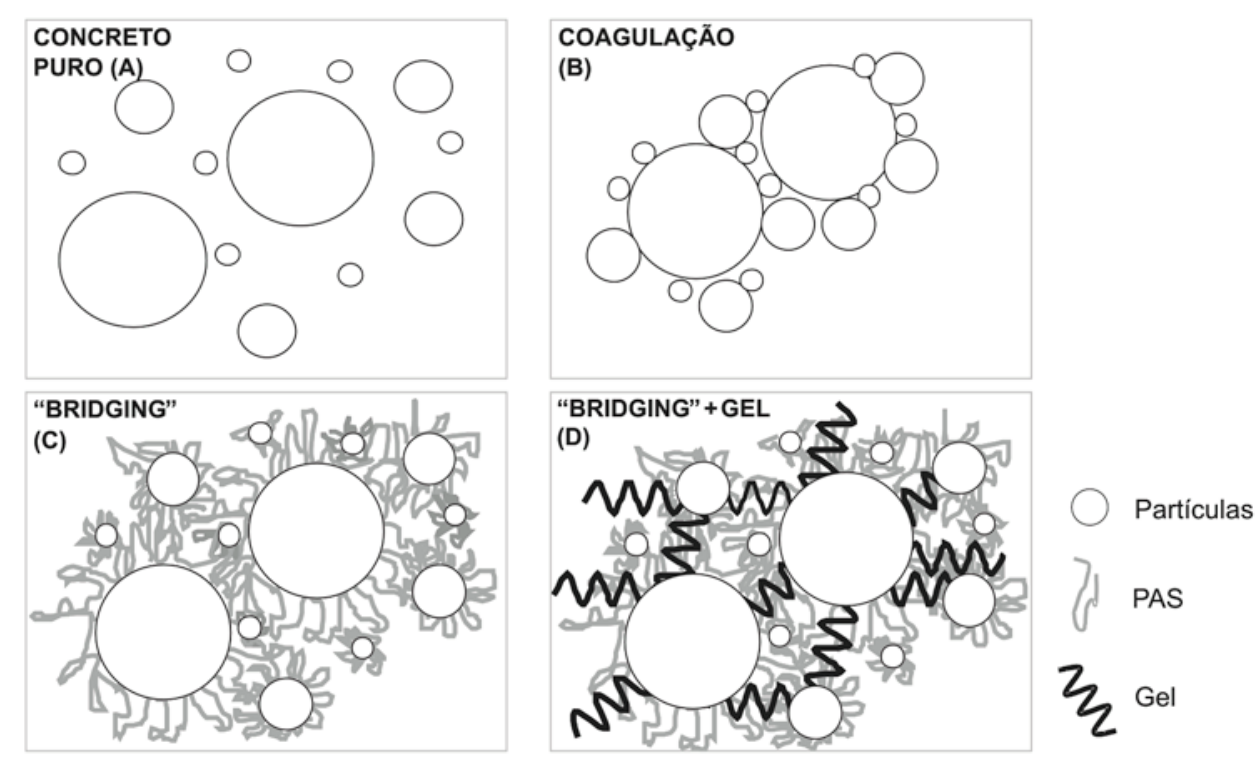

Figura 4: Mecanismos de Coagulação do Concreto: (A) Concreto sem aditivos, (B) Aglomeração devido à atração entre as partículas, (C) Efeito "bridging" causado pelas moléculas de PAS, (D) "Bridging" e formação de gel [9].

[Figure 4: Castable Coagulation Mechanisms: (A) Castable without additives, (B) Aglomeration due to attraction forces among the particles, (C) Bridging effect caused by the sodium polyacrylate (PAS) molecules, (D) Bridging effect and gel formation [9].]

destes aditivos de consolidação nas propriedades termomecânicas da matriz de concretos refratários de projeção.

\section{MATERIAIS E MÉTODOS}

O modelo de empacotamento de Andreassen [5, 12] é descrito pela equação (1), onde CPFT é porcentagem acumulada de partículas menores que um diâmetro $\mathrm{D}, \mathrm{D}_{\mathrm{L}}$ é $\mathrm{o}$ diâmetro máximo $\left(\mathrm{CPFT}=100 \%\right.$, quando $\left.\mathrm{D}=\mathrm{D}_{\mathrm{L}}\right)$ e q é o coeficiente de distribuição.

$$
\text { CPFT }=100 \times\left(\frac{D}{D_{L}}\right)^{q}
$$

Primeiramente foi formulado um concreto refratário bombeável [5] (Fig. 1A) contendo ultrabaixo teor de cimento aluminoso, baseado no modelo de Andreasen com coeficiente de empacotamento $\mathrm{q}=0,26$. A partir desta composição original, contendo $78,9 \%$ de alumina eletrofundida branca de diferentes granulometrias (Alcoa-Brasil), 20,6\% de aluminas calcinadas [tipos A1000-SG e A3000-FL (Alcoa-USA)] e 1\% de cimento aluminoso [CA-14 (Alcoa - USA)], o concreto foi reformulado para conter apenas a faixa granulométrica fina correspondente a matriz do concreto $(<100 \mu \mathrm{m})$ (Fig. 1B).

A composição da matriz estudada também apresentou um coeficiente de empacotamento de Andreassen $\mathrm{q}=0,26$, igual ao concreto que gerou a composição. A distância média entre as partículas (IPS) [5] foi de $0,077 \mu \mathrm{m}$, similar ao valor no concreto, de $0,088 \mu \mathrm{m}$. Essa matriz foi processada numa razão de $60 \%$ em volume de sólidos para $40 \%$ vol. água, o que equivale a uma quantidade de água de $18 \%$ em volume no concreto. $\mathrm{O}$ dispersante utilizado foi um policarboxilato éter (SKW - Alemanha) $(0,15 \%$ em peso).

$\mathrm{O}$ processamento das matrizes foi realizado em um misturador de bancada (Ética S.A. - Brasil) assim como a introdução do aditivo de projeção, descrito a seguir:

A) dispersão do pó seco em água sob rotação constante até a obtenção de uma suspensão fluida.

B) adição do aditivo de projeção e homogeneização por $20 \mathrm{~s}$.

C) moldagem dos corpos-de-prova para testes de resistência mecânica e fluência em altas temperaturas, os quais foram curados em atmosfera saturada ( $100 \%$ de umidade relativa) a $50{ }^{\circ} \mathrm{C}$ durante 72 horas e então secos por mais 72 horas envoltos por sílica gel, também a $50^{\circ} \mathrm{C}$.

\section{Aditivos}

Utilizando o procedimento experimental e a seqüência de ensaios descrita a seguir, três classes distintas de aditivos: inorgânicos [silicato de sódio (Aldrich-Brasil), cloreto de cálcio (Synth - Brasil)], polieletrólito orgânico [poliacrilato de sódio (Basf-Alemanha)] e um formador de gel [hidroxietil celulose QP09 (Union Carbide - Brasil)], foram testados em teores de $0,6 \%$ em peso da matriz. Além disso, sistemas combinando 0,075\% em peso de alginato de sódio (Fluka - Suíça) e poliacrilato de sódio ( $0,6 \%$ em peso), foram também estudados.

Foram selecionados aditivos com princípios distintos de coagulação para a consolidação do concreto (Fig. 4). O silicato de sódio (SS) e o cloreto de cálcio (CC) são aditivos inorgânicos comercialmente utilizados. Basicamente, os mesmos aumentam a força iônica do sistema, alterando o balanço de energia potencial e promovendo atração e aglomeração das partículas $[4,9,13]$. 
O poliacrilato de sódio (PAS) utilizado neste trabalho é um polieletrólito orgânico com elevado peso molecular $(15000 \mathrm{~g} / \mathrm{mol})$ que coagula as partículas em suspensão por mecanismos de "bridging", "depletion" e aumento na força iônica [12]. Contudo, o efeito estérico associado às suas moléculas impede que as partículas se aproximem em demasia, preservando a posição original das mesmas.

O alginato de sódio (Alg) é um polímero de alto peso molecular derivado das algas marinhas marrons $[4,9,10]$. Seu princípio de atuação é baseado na formação de um gel com a água, formando ligações cruzadas com os íons de cálcio dissolvidos a partir do cimento. Desta forma, a consolidação promovida pelo alginato não provoca a modificação da posição das partículas em suspensão.

O hidroxietil celulose (HEC) é um polímero orgânico semisintético não iônico, que se solubiliza em água, formando um gel lubrificante tixotrópico que eleva a viscosidade e a tensão de escoamento do meio líquido, sem afetar o $\mathrm{pH}$ e a força iônica do sistema $[4,10]$.

\section{Porosimetria}

Avaliou-se a porosidade total da matriz por meio do método de Arquimedes das amostras curadas e secas em sílica gel a $50{ }^{\circ} \mathrm{C}$
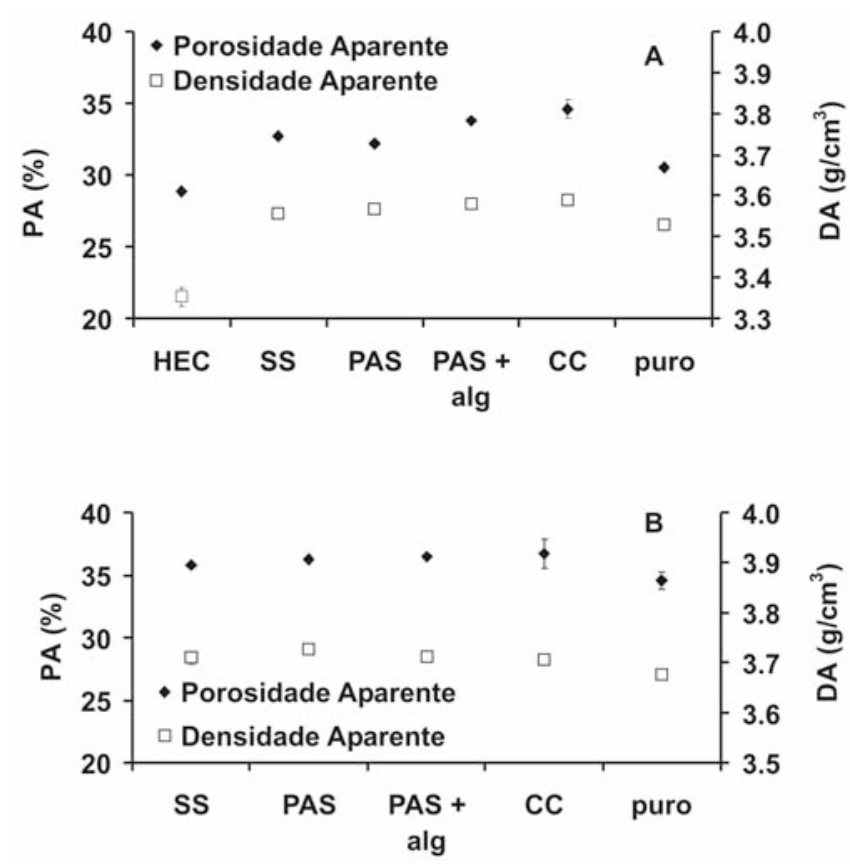

Figura 5: Influência dos aditivos de projeção sobre a porosidade densidade aparente da matriz do concreto (SS: silicato de sódio; CC: cloreto de cálcio; PAS: poliacrilato de sódio; PAS + Alg: poliacrilato + alginato de sódio; HEC: hidroxietil celulose): (A) corpos a verde (curados e secos a $\left.50{ }^{\circ} \mathrm{C}\right)$ e (B) corpos calcinados $\left(500{ }^{\circ} \mathrm{C} / 5 \mathrm{~h}\right)$.

[Figure 5: Influence of shotcrete additives on the apparent density and porosity of the castable's matrix (SS: sodium silicate; CC: calcium chloride; PAS: sodium poliacrilate; PAS + Alg: sodium poliacrilate + alginic acid salt; HEC: hidroxietil cellulose): (A) green samples (cured and dried at $50{ }^{\circ} \mathrm{C}$ ) and (B) fired samples $\left(500^{\circ} \mathrm{C} / 5 \mathrm{~h}\right)$.]

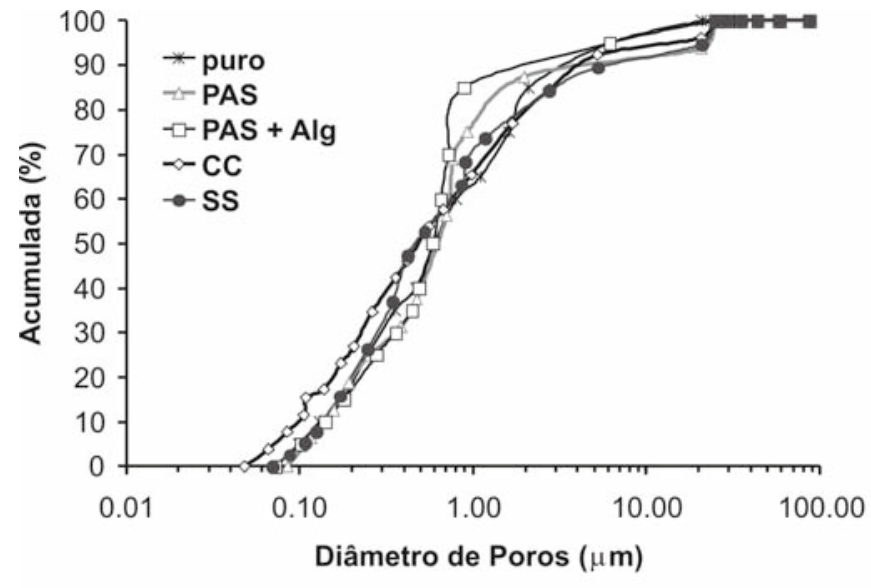

Figura 6: Influência dos aditivos de projeção sobre a distribuição de poros na matriz do concreto, após tratamento térmico a $500{ }^{\circ} \mathrm{C} / 5 \mathrm{~h}$. [Figure 6: Influence of shotcrete additives on the pore size distribution of the castable's matrix, after thermal treatment at $500{ }^{\circ} \mathrm{C} / 5 \mathrm{~h}$.]

ou pré-queimados a $500{ }^{\circ} \mathrm{C}$ por 5 horas. Utilizou-se querosene como líquido de imersão (norma ASTM C 20-87). Também foram obtidas, através de um porosímetro de mercúrio AmincoWinslow (EUA), as medidas de diâmetro de poro das amostras produzidas.

\section{Resistência mecânica}

Os corpos-de-prova utilizados para avaliar a resistência mecânica do concreto (cilindros com diâmetro (D) e altura $(\mathrm{h})=40 \mathrm{~mm}$ ) foram submetidos a testes de compressão diametral, conforme a norma ASTM C 496 - 90. A resistência mecânica foi obtida através da equação (2), onde $\sigma_{\mathrm{f}}$ é a tensão $(\mathrm{MPa})$ de ruptura do material, F é a força máxima (N) aplicada e D (m) e h (m) são respectivamente o diâmetro externo e a altura do cilindro:

$$
\sigma_{\mathrm{f}}=\frac{2 \mathrm{~F}}{\pi \mathrm{Dh}}
$$

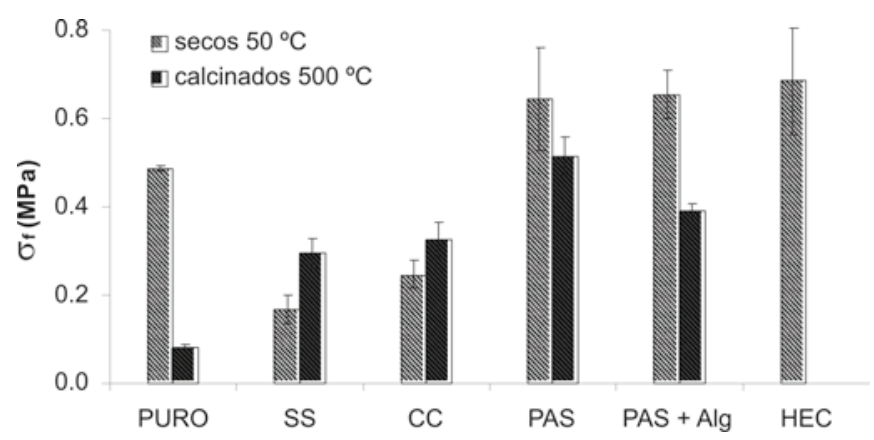

Figura 7: Influência dos aditivos de projeção sobre a resistência mecânica na matriz do concreto.

[Figure 7: Influence of shotcrete additives on the mechanical strength of the castable's matrix.] 
A resistência mecânica do material foi avaliada para 5 corpos-de-prova curados ( 72 horas) e secos a $50^{\circ} \mathrm{C}$, e também 5 corpos calcinados a $500{ }^{\circ} \mathrm{C}$ durante 5 horas, após secagem.

\section{Refratariedade sob carga efluência em altas temperaturas (Creep)}

Para estudo do comportamento de refratariedade sob carga (RUL) foram moldados corpos-de-prova cilíndricos (50 x $50 \mathrm{~mm}^{2}$ ), contendo um furo central de $12,4 \mathrm{~mm}$. Os testes foram realizados em amostras previamente pré-calcinadas a $500{ }^{\circ} \mathrm{C}$ por 5 horas, para que todos possíveis hidratos residuais pudessem ser eliminados. Para avaliação do RUL, as amostras pré-calcinadas foram aquecidas a uma taxa de $5^{\circ} \mathrm{C} / \mathrm{min}$, até temperatura de $1500{ }^{\circ} \mathrm{C}$ sob carga compressiva de $0,2 \mathrm{MPa}$ (NETZSCH - 421). Para os testes de fluência foi utilizado o mesmo equipamento e os corpos anteriormente ensaiados para o RUL. Os corpos foram aquecidos a uma taxa de $5^{\circ} \mathrm{C} / \mathrm{min}$ até a temperatura de $1500{ }^{\circ} \mathrm{C}$ e mantidos nesse patamar durante 12 horas sob carga compressiva de $0,2 \mathrm{MPa}[8,14]$.
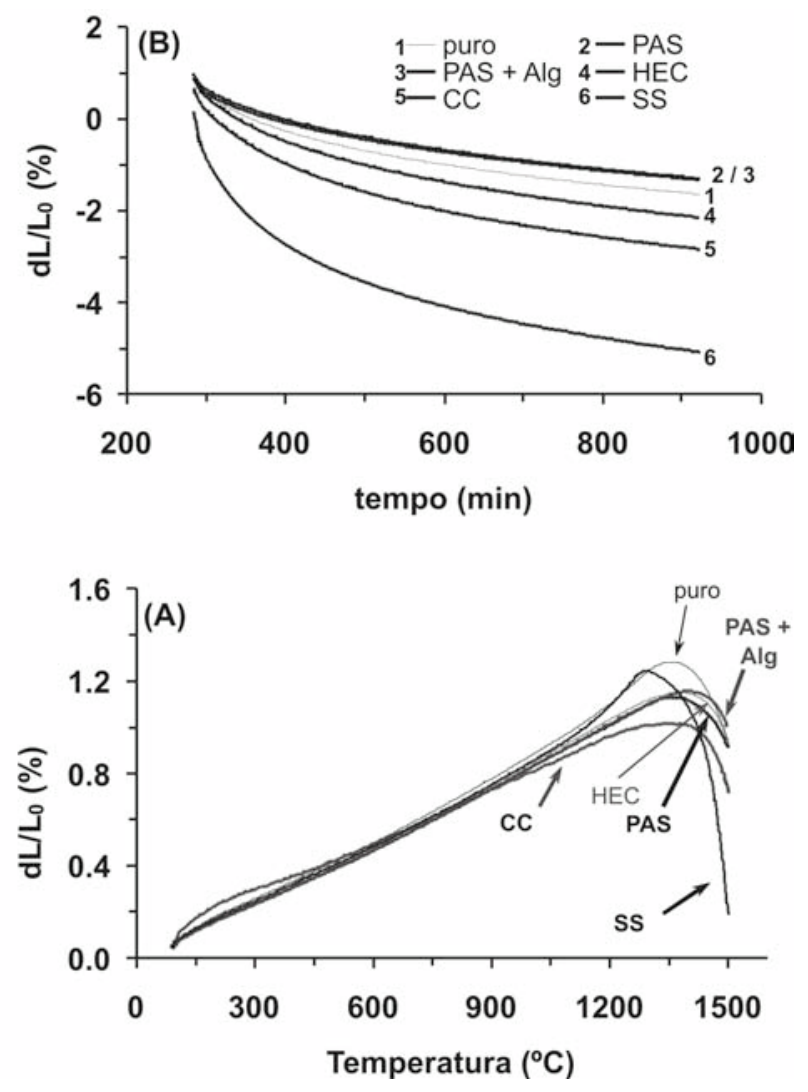

Figura 8: (A) Refratariedade sob carga para a matriz contendo os diferentes aditivos. (B) Curvas de deformação percentual $\left(\mathrm{dL} / \mathrm{L}_{0}(\%)\right)$ em função do tempo para os ensaios de fluência a $1500{ }^{\circ} \mathrm{C}$ para a matriz do concreto com diferentes aditivos.

[Figure 8: (A) Refractoriness under load for the castable's matrix with different additives. (B) Creep curves for the castable's matrix at $1500{ }^{\circ} \mathrm{C}$ with different additives.]

\section{RESULTADOS E DISCUSSÃO}

\section{Porosimetria}

As medidas de porosidade e densidade aparente (Fig. 5) mostram que estas propriedades da matriz do concreto não foram significativamente afetadas com a introdução dos aditivos, principalmente após calcinação a $500^{\circ} \mathrm{C}$ por 5 horas.

Buscando uma análise mais detalhada do impacto dos aditivos na formação de distribuição de poros na matriz do concreto de projeção, foram analisados resultados de porosimetria de mercúrio, para os corpos-de-prova calcinados a $500{ }^{\circ} \mathrm{C}$ (Fig. 6).

A fração porcentual acumulada do volume de mercúrio $(\mathrm{Hg})$ (Acumulada (\%)) em função dos diâmetros dos poros para os diferentes aditivos também não apresentou variações significativas, uma vez que o volume total de poros e o seu diâmetro médio foram bem próximos para todas as composições.

Esses resultados estão de acordo com trabalhos realizados anteriormente [15], que demonstram que essas características são governadas pelo teor de água da matriz. Por esta razão, os comportamentos observados na resistência mecânica e a fluência em alta temperatura (creep), não estarão sendo influenciados pela porosidade aparente à verde da matriz.

\section{Resistência mecânica}

Os resultados demonstraram que os diferentes aditivos de
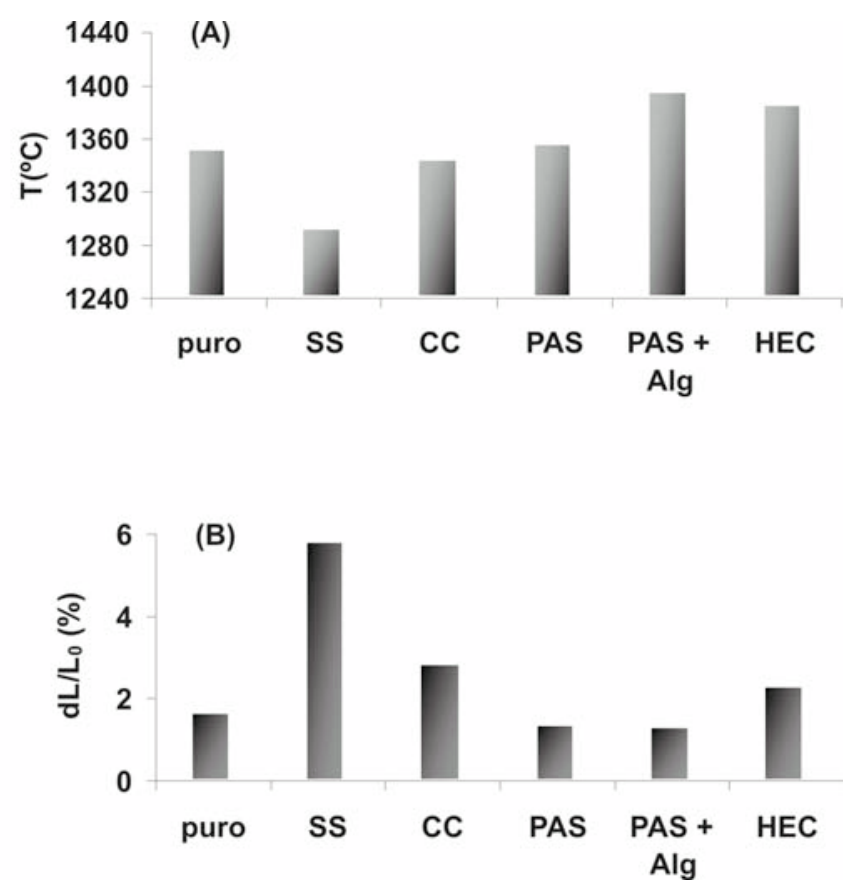

Figura 9: (A) Temperatura de início de deformação por fluência para matriz com diferentes aditivos. (B) Deformação percentual máxima $\left(\mathrm{dL} / \mathrm{L}_{0}(\%)\right)$ atingida pela matriz nos ensaios de fluência.

[Figure 9: (A) Starting temperature for creep flow of the matrix with different additives. (B) Maximum percentual strain $\left(d L / L_{0}(\%)\right)$ achieved by the matrix during creep test.] 
projeção afetaram distintamente a resistência mecânica da matriz (Fig. 7), sendo possível diferenciar a atuação dos aditivos inorgânicos e orgânicos.

Tanto o silicato de sódio (SS) quanto o cloreto de cálcio (CC), ambos aditivos inorgânicos, diminuíram a resistência da matriz seca a $50{ }^{\circ} \mathrm{C}$. A combinação do SS com o cimento aluminoso eleva os níveis de pH da matriz [4, 12], causando uma aglomeração intensa das partículas. Esse efeito influencia diretamente a força de ligação da matriz, podendo assim gerar uma estrutura mais fraca [4]. Além disso, o SS é um forte retardador de pega, promovendo a formação de outros produtos $\left(2 \mathrm{CaO} \cdot \mathrm{Al}_{2} \mathrm{O}_{3} \cdot \mathrm{SiO}_{2} \cdot 8 \mathrm{H}_{2} \mathrm{O}\right)$ que impedem a hidratação do cimento [13]. Este fato explica a baixa resistência desenvolvida pelo material com este aditivo, seco a $50{ }^{\circ} \mathrm{C}$.

Já o cloreto de cálcio (CC) é um acelerador da hidratação do cimento [2, 3]. Desta forma, a baixa resistência da matriz com este aditivo pode estar associada à sua ação aglomerante, podendo também gerar uma estrutura menos resistente.

Durante o aquecimento, ocorre a decomposição dos hidratos formados pela reação do cimento e a água, causando perda das ligações hidráulicas. Entretanto, os aditivos inorgânicos aumentaram a resistência mecânica para níveis acima daqueles alcançados pela matriz pura após a calcinação a $500{ }^{\circ} \mathrm{C}$. Este fato pode estar relacionado a formação de outras fases ligantes em substituição às ligações hidráulicas.

Aditivos orgânicos, poliacrilato de sódio (PAS), hidroxietil celulose (HEC) e a combinação de poliacrilato e alginato de sódio (PAS + Alg) aumentaram a resistência mecânica da matriz tanto seca a $50{ }^{\circ} \mathrm{C}$ quanto após a calcinação. O ganho de resistência a verde promovido pelo PAS e a combinação PAS + Alg pode ser atribuída às cadeias poliméricas $\left(50^{\circ} \mathrm{C}\right) \mathrm{e}$ a formação de géis $\left(50^{\circ} \mathrm{C}\right.$ e $\left.500{ }^{\circ} \mathrm{C}\right)$, que geram uma estrutura tridimensional de ligações entre as partículas.

\section{Fluência em altas temperaturas (Creep)}

O comportamento de fluência da matriz pode ser analisado

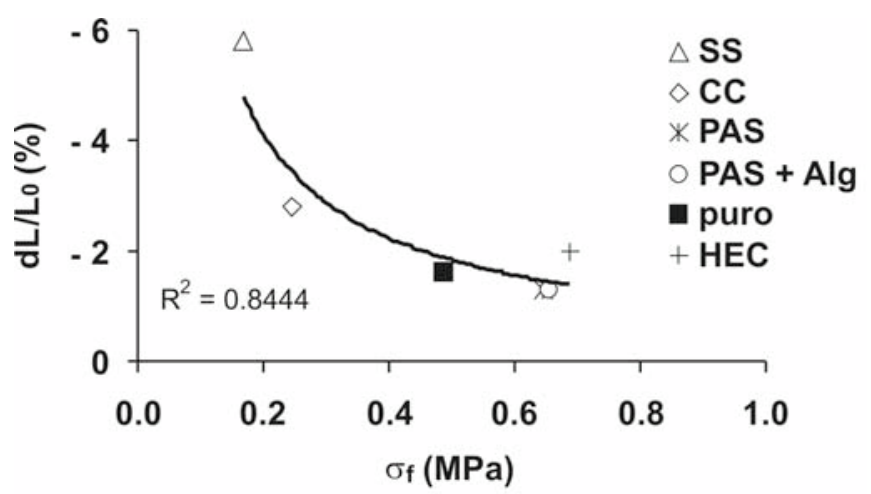

Figura 10: Deformação máxima por fluência $\left(\mathrm{dL} / \mathrm{L}_{0}\right)$ versus resistência mecânica $\left(\sigma_{\mathrm{f}}\right)$ para os corpos à verde (curados e secos a $50^{\circ} \mathrm{C}$ ).

[Figure 10: Maximum creep strain $\left(d L / L_{0}\right)$ versus mechanical strength $(\sigma)$ for the unfired castables' samples (cured and dried at $50{ }^{\circ} \mathrm{C}$ ).] através das curvas de deformação percentual $\left(\mathrm{dL} / \mathrm{L}_{0}\right)$ em função da temperatura (até $1500^{\circ} \mathrm{C}$ ) e do tempo (Fig. 8). Nesta análise os resultados mostram que os aditivos influenciam significativamente a resistência a fluência em altas temperaturas.

O uso do silicato de sódio (SS) resultou a maior deformação na matriz do concreto. Além disso, este aditivo fez com que o corpo iniciasse a deformação em uma temperatura inferior aos demais aditivos, inclusive da matriz pura (Fig. 9). Este fato pode ser associado à formação de uma fase vítrea a alta temperatura (sistema $\mathrm{Na}_{2} \mathrm{O} \cdot \mathrm{SiO}_{2} \cdot \mathrm{Al}_{2} \mathrm{O}_{3} \mathrm{CaO}$ ).

$\mathrm{O}$ cloreto de cálcio (CC) ocasionou uma deformação superior ao material sem aditivos. Contudo, seu efeito foi menos intenso quando comparado ao SS. Desta maneira, os aditivos inorgânicos apresentaram os piores resultados quanto ao comportamento de fluência em altas temperaturas.

O hidroxietil celulose, aditivo formador de gel, resultou uma deformação máxima inferior aos aditivos inorgânicos, mas superior à matriz pura (Fig. 8). Isso indica que o aditivo não afeta intensamente o comportamento de fluência do material. Ainda assim, este aditivo resultou em um aumento da temperatura de início de deformação na matriz (Fig. 9).

O poliacrilato (PAS) e a combinação do poliacrilato com alginato (PAS) apresentaram comportamentos muito similares quanto a fluência em altas temperaturas. Ambos aditivos retardaram o início da deformação, deslocada para uma maior temperatura (Fig. 9). Além disso, estes aditivos orgânicos reduziram a deformação máxima alcançada pela matriz, melhorando o desempenho do material.

Relacionando os resultados de resistência mecânica de corpos a verde e da deformação máxima por fluência (Fig. 10), pode-se observar uma certa tendência experimental entre os aditivos.

Os aditivos que apresentam menores valores de deformação por fluência apresentam maiores valores de resistência mecânica à verde $\left(50^{\circ} \mathrm{C}\right)$. Os aditivos industriais, que apresentam maiores deformações, não promovem alta resistência mecânica. Isso comprova a ineficiência dos aditivos industriais (SS e CC) em manter as propriedades termomecânicas do material.

Já os aditivos orgânicos baseados em poliacrilato de sódio (PAS e PAS + Alg), melhoraram as propriedades termomecânicas da matriz, combinando baixa deformação e alta resistência mecânica nas condições avaliadas neste estudo.

Do ponto de vista das aplicações, onde o volume de material e a porcentagem de aditivo na matriz podem ser superiores [1, 3], o efeito nas propriedades do concreto podem ser mais intensos. Portanto, um outro critério para a seleção de aditivos de projeção, além do nível de rebote [2-4] e efeito na secagem [9], deve ser sua influência nas propriedades termomecânicas na matriz do concreto.

\section{CONCLUSÕES}

A introdução de aditivos coagulantes influenciou profundamente as propriedades termomecânicas da matriz de concretos de projeção. Os aditivos orgânicos contendo 
poliacrilato de sódio (PAS e PAS + Alg) promoveram ganhos de desempenho da matriz em todas as propriedades analisadas.

Aditivos inorgânicos utilizados industrialmente que induzem a aglomeração das partículas (silicato de sódio e cloreto de cálcio) reduziram a resistência mecânica dos corpos à verde. Além disso, o cloreto de cálcio e, mais intensamente, o silicato de sódio levaram a uma maior deformação da matriz por fluência em altas temperaturas (creep), deslocando o início da deformação para temperaturas inferiores à da matriz sem aditivos.

Tanto o poliacrilato de sódio (PAS) quanto a combinação poliacrilato e alginato de sódio (PAS + Alg) aumentaram a resistência mecânica da matriz à verde e também após calcinação. Esses aditivos também promoveram a menor fluência da matriz em altas temperaturas (creep), resultando em níveis inferiores à matriz pura, com início de deformação em temperaturas mais elevadas. São, portanto, aditivos que devem ser considerados para utilização em concretos refratários aplicados por projeção a úmido.

\section{AGRADECIMENTOS}

Os autores agradecem a FAPESP, ao CNPq e a ALCOA Alumínio S.A. pelo apoio dado à execução deste trabalho e ao pesquisador Sérgio F. dos Santos pelas suas colaborações.

\section{REFERÊNCIAS}

[1] I. L. Glassgol, Refractory shotcrete - the current state of art, Shotcrete Magazine, Summer issue (2002) 24-32.

[2] M. Jolin, D. Beaupré, S. Mindess, Tests to characterize properties of fresh dry-mix shotcrete, Cement and Concrete Research 29 (1999) 753-760.

[3] L. R. Prudêncio Jr., Accelerating admixtures for shotcrete, Cement and Concrete Research 20 (1998) 213-219.

[4] R. G. Pileggi, Y. A Marques, D. Vasques Filho, A. R. Studart, V. C. Pandolfelli, Wet-Shotcrete Additives, Am. Ceram. Soc.
Bull. 81, 61 (2002) 51-57.

[5] R. G. Pileggi, V. C. Pandolfelli, Rheology and particle size distribution of pumpable refractory castables, Am. Ceram. Soc. Bull. 80, 10 (2001) 52-57.

[6] R. G. Pileggi, Y. A Marques, D. Vasques Filho, V. C. Pandolfelli, Shotcrete performance of refractory castables, Refractories Applications 8, 3 (2003) 15-20.

[7] D. Vasques Filho, Y. A. Marques, R. G. Pileggi, V. C. Pandolfelli, Impacto do uso de fibras poliméricas no desempenho de concretos refratários aplicados por projeção, Cerâmica 50, 313 (2004) 69-74.

[8] R. G. Pileggi, F. T. Ramal Jr, A. E. Paiva, V. C. Pandolfelli, High performance refractory castables: Particle size design, Refractories Applications 8, 5 (2003) 17-21.

[9] Y. A. Marques, D. Vasques Filho, R. G. Pileggi, V. C. Pandolfelli, Influência dos aditivos sobre a permeabilidade e a velocidade de secagem de concretos refratários aplicados por projeção, Cerâmica 50, 313 (2004) 07-11.

[10] K. H. Khayat, Viscosity enhancing admixtures for cementbased materials: An overview, Cement and Concrete Research, 20 (1998) 171-188.

[11] A. R. Studart, V. C. Pandolfelli, E. Tervoot, L. J. Gauckler, Gelling of alumina suspensions using alginic acid salt and hydroxyaluminum diacetate, J. Am. Ceram. Soc. 85, 11 (2002) 2711-2718.

[12] I. R. Oliveira, A. R. Studart, R. G. Pileggi, V. C. Pandolfelli, Dispersão e empacotamento de partículas: princípios básicos e aplicações em processamento cerâmico, Fazendo Arte Editorial, S. Paulo, SP (2000) 224 p.

[13] J. Ding, Y. Fu, J. J. Beaudoin, Study of hydration mechanisms in high alumina cement - sodium silicate system, Cement and Concrete Research 26, 5 (1996) 799-804.

[14] D. J. Bray, J. R. Smyth, T. D. McGee, Creep of 90+\% Alumina Concrete, Am. Ceram. Soc. Bull. 59, 7 (1980) 706-10. [15] F. T. Ramal Jr, R. Salomão,V. C. Pandolfelli, Comportamento de secagem e explosão de concretos refratários com diferentes teores de água, Cerâmica 50, 315 (2004) 197-201

(Rec. 30/01/04. Ac. 05/03/04) 